\title{
STUDY ON GREEN WATER OF TUMBLEHOME HULL USING DAM-BREAK FLOW AND RANSE MODELS
}

\author{
Shuzheng Sun, Assoc. Prof. Ph.D. \\ Wenlei Du, M.S. \\ Hui Li, Assoc. Prof. Ph.D. \\ College of Shipbuilding Engineering, Harbin Engineering University, Harbin, Heilongjiang, China
}

\begin{abstract}
The tumblehome hull adopts some novelty designs such as low-tumblehome freeboard and wave-piercing bow. The new form design makes the ship have many special hydrodynamic performances. Especially the green water of tumblehome hull is different from that of hulls with flare free board. Green water is a strong nonlinear phenomenon of ship-wave interaction, the variation of free surface of liquid is complicated, and there are still some difficulties to solve green water problems well with numerical simulation method. In this paper firstly the motion responses of the tumblehome hull was calculated based on 3D potential theory, and then the dam-break flow model was used to calculate green water height and pressure distribution. According to the result of numerical simulation, some typical working conditions are chosen for $3 D$ CFD simulation using RANS method. The results of numerical simulation methods are compared with the experimental results measured in towing tank. The influence of different ship form parameters and wave parameters to the green water of tumblehome hull is analyzed, and some regularities of green water on tumblehome hull in regular waves are summarized.
\end{abstract}

Keywords: Tumblehome hull; Green water; Dam-break flow; RANSE

\section{INTRODUCTION}

The tumblehome hull adopts some novelty designs such as low-tumblehome freeboard and wave-piercing bow $[1,2]$. Compared with flare designed hull forms, the tumblehome hull has better stealth performance [3], lower resistance and better longitudinal motion performance. However, for the low and intilted free board of wave-piercing bow, the wave split by wave-piercing bow can flood the deck easily, and some devices will be impacted seriously by the rushing water on the deck. Therefore, it is important to investigate the pressure distribution on deck, green water height and green water regularities of tumblehome hull.

Many researchers investigated green water of ships based on numerical simulation and model test. Pham [4] carried out a simplified numerical simulation of green water on the S175 high speed container ship by dam-break flow model, then obtained the impact loads on deck and applied to the analysis of wave proof effect. ZHANG[5] and Yonguk[6] give the dam-break flow wave solutions for green water. Sames[7] took a simulation of green water on a moving passenger liner by the solver COMET using RANS method. LIANG[8] et al. researched the problem of green water on $3 \mathrm{D}$ FPSO model by founding a numerical tank, the results are similar to the experimental phenomena. However, the research of green water on tumblehome hull is rarely. FUNENO[9] and Liu[10] solve green water problems using SPH method. Go'mez-Gesteira[11], Touzé[12] and Kristian[13] analyzed green water of ships use viscous flow theory. By analyzing 
the phenomenon of green water on tumblehome hull, to understand the law of green water, through the rational design of ship type parameters to improve the phenomenon of green water on tumblehome hull, these can make the study has some practical significance.

In this paper, the work mainly pointed to 5 types of tumblehome hull models with different stem inclination angle and freeboard inclination angle. Firstly, 3D potential flow theory is used to calculate the motion response in regular waves. Then dam-break flow model is used to calculate the height and pressure distribution of green water. By studying the effect of wave and ship form parameters on green water the green water characteristics of the tumblehome hull is analyzed. According to the calculation results, three typical working conditions are chosen to carry out 3D numerical simulation with RANS method. Finally, comparing the results of numerical simulation methods with the results of model test in towing tank, some regularities of green water on tumblehome hull in waves are summarized, and some suggestions for design in tumblehome hull are presented.

\section{NUMERICAL CALCULATION MODELS}

In head waves, the principle longitudinal motions of ships include heaving and pitching. Based on the linear theory of ship motions, ignoring the interference of hull to waves, the nominal relative motion of the ship can be expressed as:

$$
S_{R}^{0}(t)=-z(t)+x_{q} \theta(t)+\zeta(t)
$$

Where: $z(t)$ is the heaving of the ship; $\theta(t)$ is the pitching angle of the ship; $x_{q}$ is the distance between the considering point and the center of gravity of the ship; $\zeta(t)$ is the amplitude of incident wave.

The expression of the relative motion $S_{R}$ of wave is:

$$
S_{R}=S U C \times S_{R}^{0}
$$

Where: SUC is the step-up ratio of the relative motion, $S_{R}^{0}$ is nominal relative motion of the ship.

If the water is over the freeboard as expressed in formula (3), the green water occurs:

$$
S_{R}=h_{f}
$$

Where: $h_{f}$ is the freeboard of the bow, $S_{R}$ is the relative motion of wave for floating.

Dam-break flow model is a kind of shallow water wave model, which does not concern inertia force effect. Ignoring the inertia force, Saint-Venant Equations can be simplified as follows:

$$
\left\{\begin{array}{c}
\frac{\partial h}{\partial t}+h \frac{\partial V}{\partial x}+V \frac{\partial h}{\partial x}=0 \\
\frac{\partial h}{\partial x}+\frac{V^{2}}{C^{2} R}-i_{b}=0
\end{array}\right.
$$

The coefficient $\mathrm{C}$ can be expressed as:

$$
\mathrm{C}=\frac{1}{n} R^{1 / 6}
$$

Where: $\mathrm{n}$ is manning roughness.

For formula 5 into formula 4:

$$
\frac{\partial h}{\partial x}=i_{b}-\frac{n^{2} V^{2}}{R^{4 / 3}}
$$

Then get the partial derivative of $x$ on both sides of the form. Oder $R \approx h$.

$$
\frac{\partial V}{\partial x}=\frac{2 V}{3 h} \frac{\partial h}{\partial x}-\frac{h^{4 / 3}}{2 n^{2} V} \frac{\partial^{2} h}{\partial x^{2}}
$$

For formula 7 into formula 4 :

$$
\frac{\partial h}{\partial t}=D \frac{\partial^{2} h}{\partial x^{2}}-C_{d} \frac{\partial h}{\partial x}
$$

Where: $D=\frac{h^{7 / 3}}{2 n^{2} V}=\frac{V h}{2\left(i_{b}-\frac{\partial h}{\partial x}\right)}, C_{d}=\frac{5}{3} V$.

The formulas above are the flood diffusion wave equation, which the following solution can be get through the Laplace transform:

$$
\begin{aligned}
h(x, t) & =\frac{h_{c}}{\sqrt{4 \pi D}} \int_{0}^{t} \frac{x}{t^{3 / 2}} \exp \left[-\frac{\left(C_{d} t-x\right)^{2}}{4 D t}\right] d t \\
& =\frac{h_{c}}{2}\left\{1-\operatorname{erf}\left(\frac{x}{2 \sqrt{D t}}-\frac{C_{d}}{2} \sqrt{\frac{t}{D}}\right)\right\} \\
& =e^{C_{d} x / D}\left[1-\operatorname{erf}\left(\frac{x}{2 \sqrt{D t}}+\frac{C_{d}}{2} \sqrt{\frac{t}{D}}\right)\right]
\end{aligned}
$$

Figure 1 shows dam-break flow model used in green water calculation.

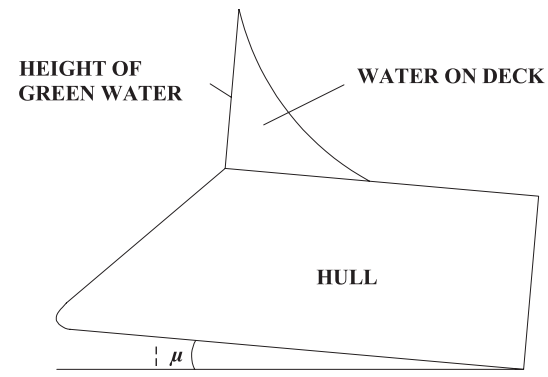

Fig. 1. Application of dam-break flow model on green water

The maximum time of $S_{R}$ is taken as the initial time of the flow calculation. Considering the influence of the variation of the width of the deck on the variation of the height of green water, the height of the green water can be linearly corrected: 


$$
h^{\prime}\left(x_{f}^{\prime}, t\right)=\frac{B_{0}}{B\left(x_{f}^{\prime}\right)} h\left(x_{f}^{\prime}, t\right)
$$

Where: $B\left(x_{f}^{\prime}\right)$ is the deck width at $x_{f}^{\prime}, B_{0}$ is the initial width of green water.

After getting the space-time distributing of height of green water, the momentum theorem is used for considering the dynamic effect of flood peak. The pressure expression is as follows:

$$
P_{G W}=\rho h\left(g \cos \theta+\frac{\partial V_{D}}{\partial t}\right)+\rho\left(\frac{\partial h}{\partial t}\right) V_{D}
$$

Where: $\rho$ is the density of water; h is the height of green water; $V_{D}$ is the vertical velocity of deck; $\theta$ is the trim angle of deck.

The first step of CFD simulation of green water is to establish the numerical wave tank, which is shown in Figure 2. Then the regular wave of different parameters are simulated based on unlimited depth wave theory. The size of the numerical wave tank is set up the same as the physical towing tank, and the parameters are as follows: the length, width and height are $108 \mathrm{~m}, 7 \mathrm{~m}$ and $3.5 \mathrm{~m}$, respectively. . The scale ratio of the calculated model is $1 / 40$, which is the same as the tested model in the towing tank. The numerical wave tank has three regions such as the wave-generating region, the work region and the wave-absorbing region. Numerical simulation of turbulent flow employs the Reynolds Average Navier-Stokes (RANS) method. The control equations for the flow field include the continuity equation (12) and N-S equation (13).

$$
\begin{gathered}
\frac{\partial \rho}{\partial t}+\frac{\partial\left(\rho u_{i}\right)}{\partial x_{i}}=0(i=1,2,3) \\
\frac{\partial\left(\rho u_{i}\right)}{\partial t_{i}}+\frac{\partial\left(\rho u_{i} u_{j}\right)}{\partial x_{i}}=\frac{\partial}{\partial x_{j}}\left[\mu\left(\frac{\partial u_{i}}{\partial x_{j}}+\frac{\partial u_{j}}{\partial x_{i}}\right)\right]-\frac{\partial p}{\partial x_{i}}+S_{i}+\rho f_{i}
\end{gathered}
$$$$
(i=1,2,3)
$$

Where: $\rho$ is the density of water; $\mu$ is the coefficient of dynamic viscosity; $f_{i}$ is the mass force; $S_{i}$ is the additional momentum source term.

For the numerical calculation, RNG k- $\varepsilon$ model is used, and VOF method is used to solve the multiphase problems. The computation domain and boundary conditions are set up as Figure 2 shows.

According to the results of the potential flow theory, the working condition of $\mathrm{H}=9 \mathrm{~m}, \lambda / L=0.8,1.0$ and 1.2 are chosen as the typical conditions. Using the basic ship configuration $\mathrm{C}\left(\alpha=45^{\circ}, \beta=10^{\circ}\right)$ to calculate green water load at the speed of $0 \mathrm{kn}$ and $18 \mathrm{kn}$. CFD numerical simulation is carried out on scale model with scale ratio 1:40. The calculation results are the results at model scale.

Tab. 1. CFD simulation calculation parameters

\begin{tabular}{ccc}
\hline & Real ship & CFD model \\
$H$ (Wave height) & $9 \mathrm{~m}$ & $0.225 \mathrm{~m}$ \\
1 (Wavelength) & $144 \mathrm{~m}, 180 \mathrm{~m}, 216 \mathrm{~m}$ & $3.6 \mathrm{~m}, 4.5 \mathrm{~m}, 5.4 \mathrm{~m}$ \\
$V s$ (Speed) & $0 \mathrm{kn}, 18 \mathrm{kn}$ & $0 \mathrm{~m} / \mathrm{s}, 1.46 \mathrm{~m} / \mathrm{s}$ \\
\hline
\end{tabular}

\section{RESULTS AND DISCUSSIONS}

The principal dimensions of the computational model are as follows: The length of waterline $(L)$ is $180 \mathrm{~m}$, the width of waterline $(B)$ is $20.99 \mathrm{~m}$, the depth $(D)$ is $15 \mathrm{~m}$ and the draft $(T)$ is $7 \mathrm{~m}$.

Figure 3 gives the definition of the stem inclination angle $(\alpha)$ and freeboard inclination angle $(\beta)$. The computational model refers to different $\alpha$ and $\beta$ using orthogonal combination method to obtain 5 types of hull design named configuration $\mathrm{A}\left(\alpha=30^{\circ}, \beta=10^{\circ}\right)$, configuration $\mathrm{B}\left(\alpha=45^{\circ}, \beta=7^{\circ}\right)$, configuration $\mathrm{C}\left(\alpha=45^{\circ}, \beta=10^{\circ}\right)$, configuration $\mathrm{D}\left(\alpha=45^{\circ}, \beta=13^{\circ}\right)$ and configuration $\mathrm{E}\left(\alpha=60^{\circ}, \beta=10^{\circ}\right)$. The freeboard inclination angle caused by the difference is mainly reflected in the ship line above the free surface. Configuration B, C and D adopt

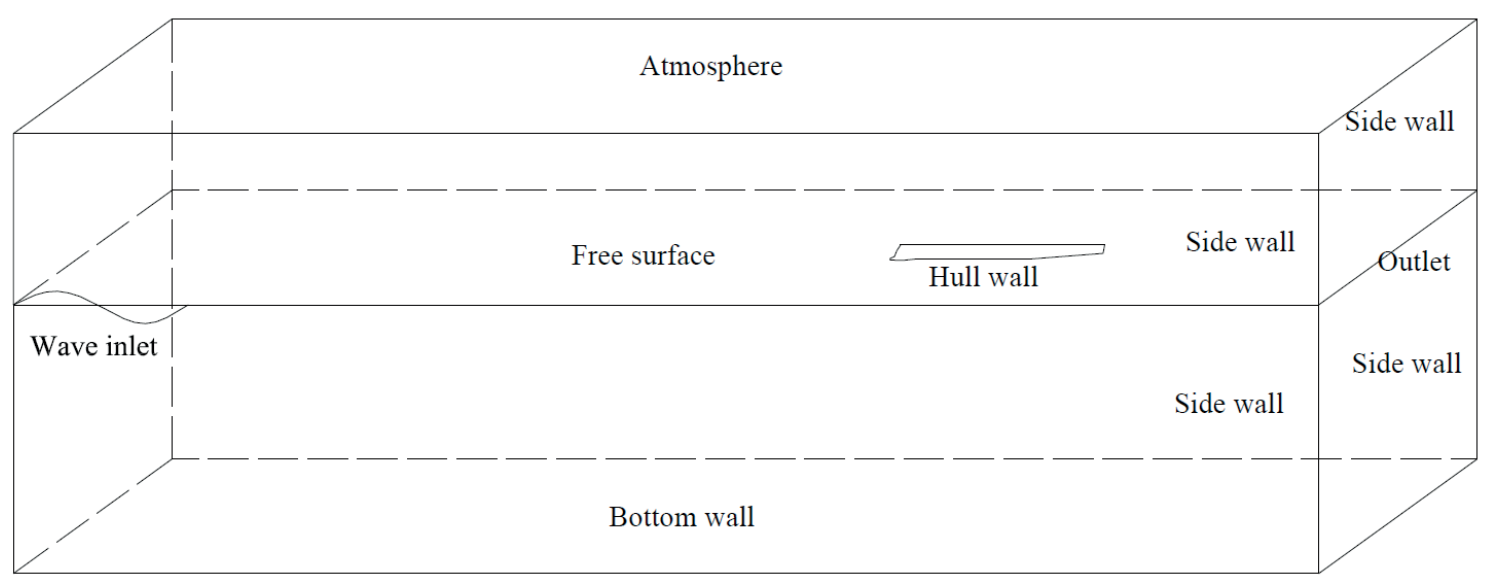

Fig. 2. Computation domain and boundary conditions 
the same calculation model. The calculated speed of the hull and the wave parameters are shown in Table 2.
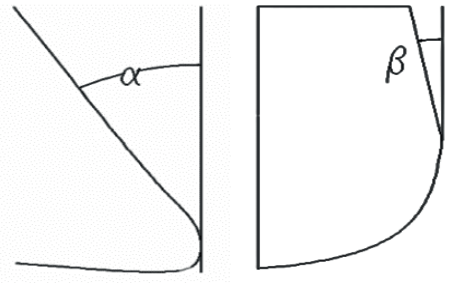

Fig. 3. Sketch of inclination angle

Tab. 2. Environmental parameters of numerical calculation

\begin{tabular}{cc}
\hline Real ships speeds $(\mathrm{kn})$ & $0,10,18,30$ \\
Wave direction $\left(^{\circ}\right)$ & 180 \\
Frequency of waves $(\mathrm{rad} / \mathrm{s})$ & $0.65,0.59,0.53$ \\
\hline
\end{tabular}

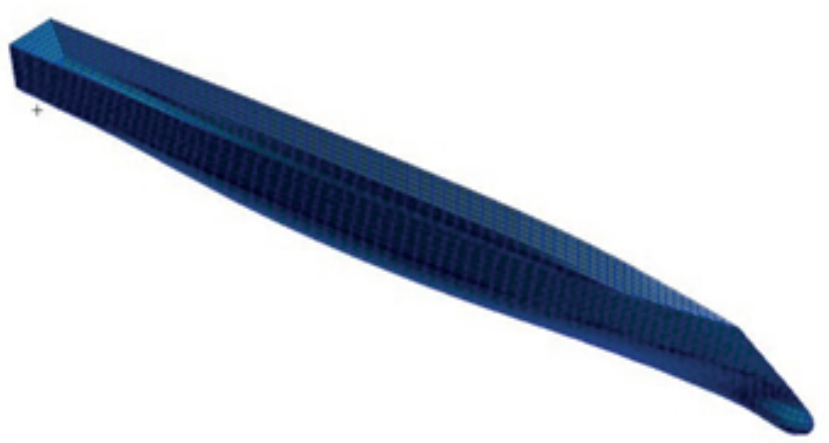

Fig. 4. Sketch of panel model and the hydrodynamic grid $\left(\alpha=60^{\circ}, \beta=10^{\circ}\right)$

The panel model for computational is shown in Figure 4. The motions of tumblehome hull in regular waves are calculated by using 3D wave loads calculation code WALCS. The calculation results are shown in Figure 5. From Figure 5 it can be found that the motion response of configuration $\mathrm{A}$ is minimum and configuration $\mathrm{E}$ is maximum at $0 \mathrm{kn}$. The motion response of three configurations are consistent at $10 \mathrm{kn}$. The motion response of configuration $\mathrm{C}$ is minimum and the motion response of configuration $\mathrm{A}$ is maximum at $18 \mathrm{kn}$. Moreover, the motion response of configuration A is minimum and the motion response of configuration $\mathrm{C}$ is maximum at $30 \mathrm{kn}$.

According to the motion prediction results of the ship, typical calculation conditions are set to calculate the height and pressure of green water by using dam-break flow model. According to the calculation results of configuration $\mathrm{C}\left(\alpha=45^{\circ}\right.$, $\left.\beta=10^{\circ}\right)$, the influence of environmental parameters on green water is analyzed.

As shown in Figure 6, as $\mathrm{H}=9 \mathrm{~m}, \lambda / L=0.8,1.0$, the height and pressure of green water first increase then decrease. As $\lambda / L=0.8$, the maximum value appears near the speed of $10 \mathrm{kn}$. As $\lambda / L=1.0$, the maximum value appears near the speed of
$20 \mathrm{kn}$. As $\lambda / L=1.2$, the height and pressure of green water increase with the increase of speed.

In order to study the influence of wave height on green water, height and pressure of green water under different wave height are analyzed. Wave height has direct influence on height and pressure of green water. The wave height increases, the height and pressure of green water also increased. The calculation results of the height and pressure of green water are shown in Figure 7 Figure 11. The numerical simulation result of the wave tank is like Figure 12 shown.

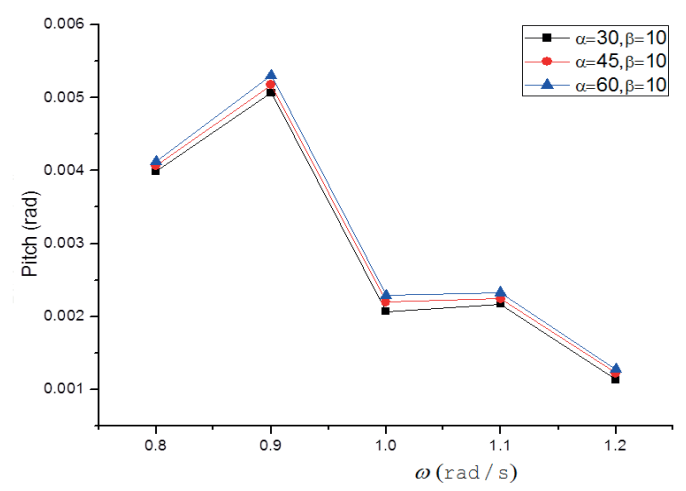

(a) Pitch response $(v=0 \mathrm{kn})$

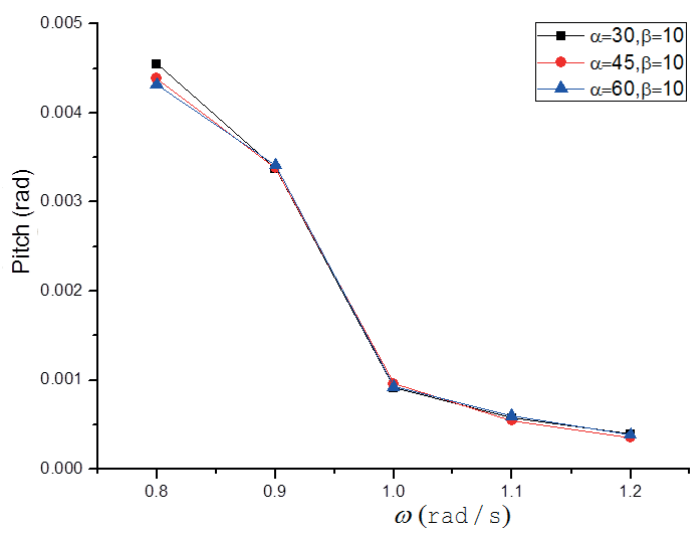

(b) $V s=10 \mathrm{kn}$

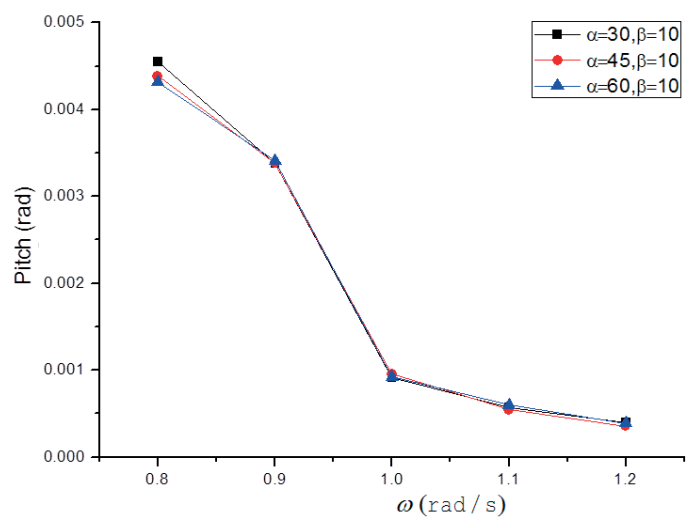

(c) $V s=18 \mathrm{kn}$ 


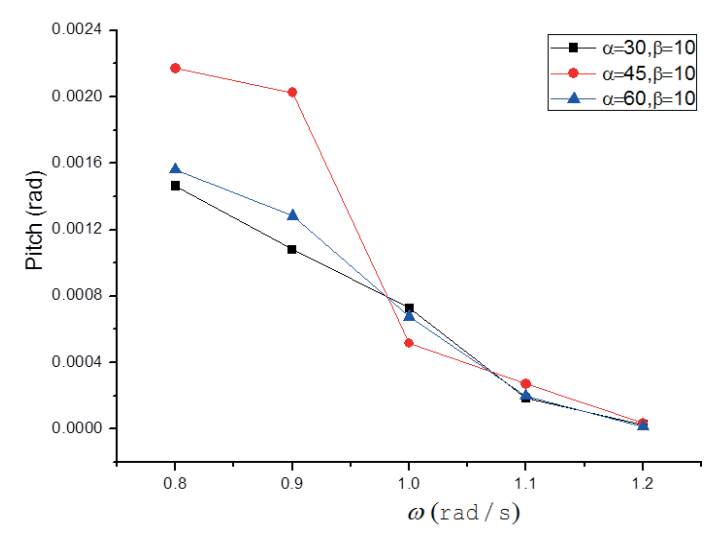

(d) $V s=30 \mathrm{kn}$

Fig. 5. The pitching angle response of tumblehome hull (Pitch)

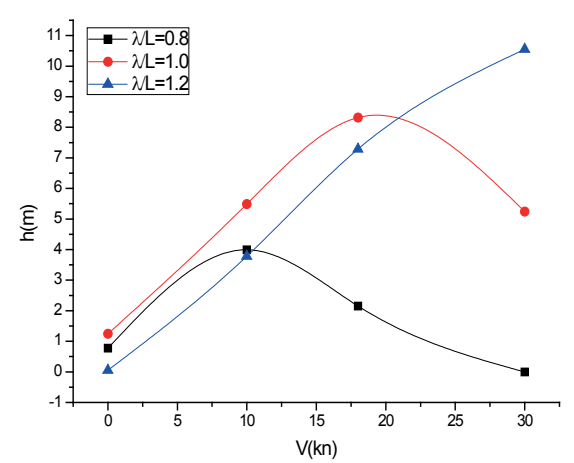

(a)Height of green water

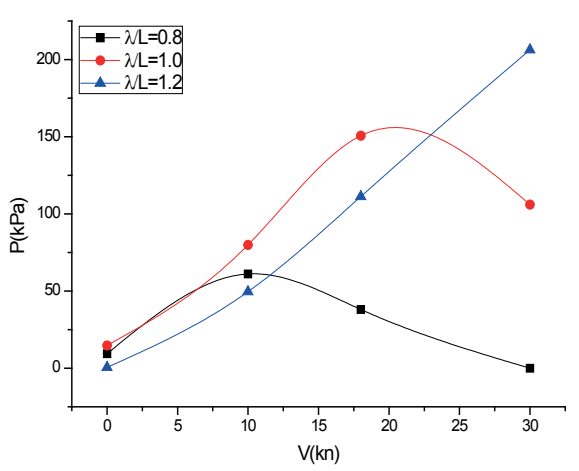

(b) Pressure of green water

Fig. 6. The height and pressure of green water of different $l / L(H=9 m)$

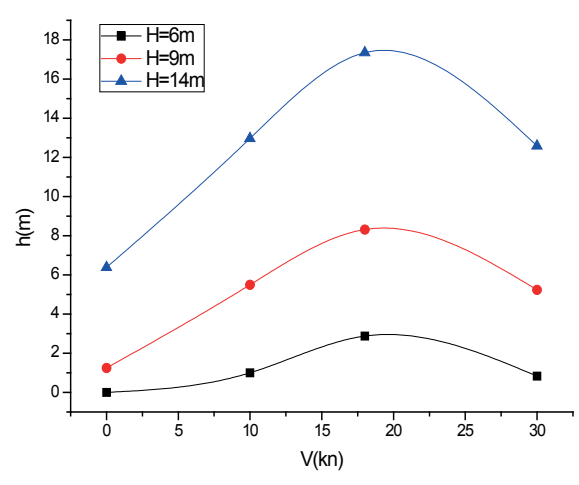

(a)Height of green water

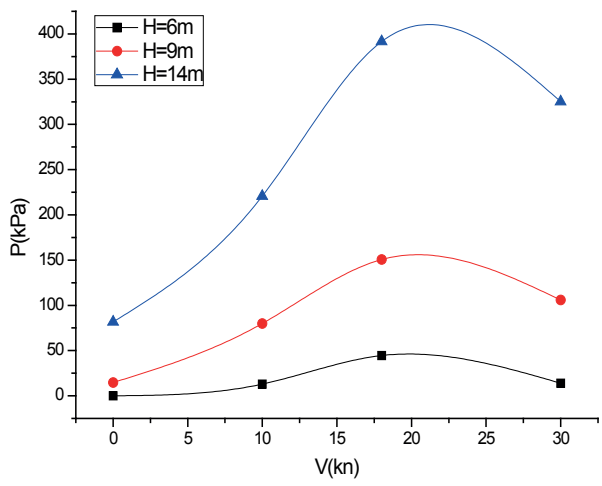

(b) Pressure of green water

Fig. 7. Green water height and pressure of different wave heights $(\lambda / L=1.0)$

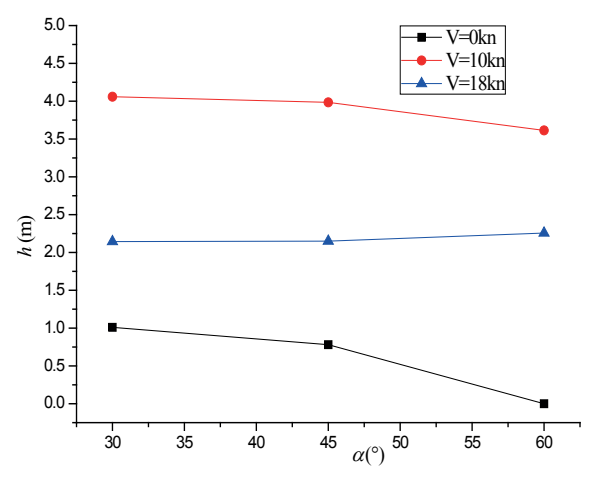

(a)Height of green water

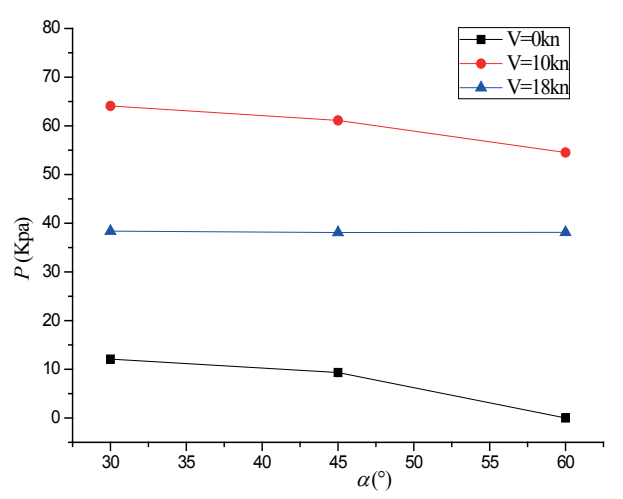

(b) Pressure of green water

Fig. 8. Green water height and pressure of different $a(\lambda / L=0.8, H=9 m)$

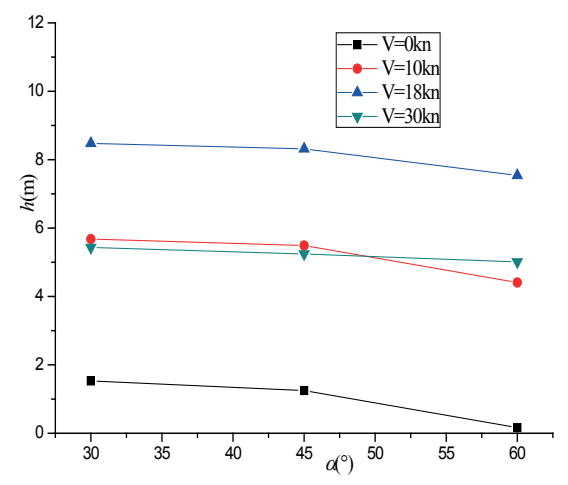

(a)Height of green water 


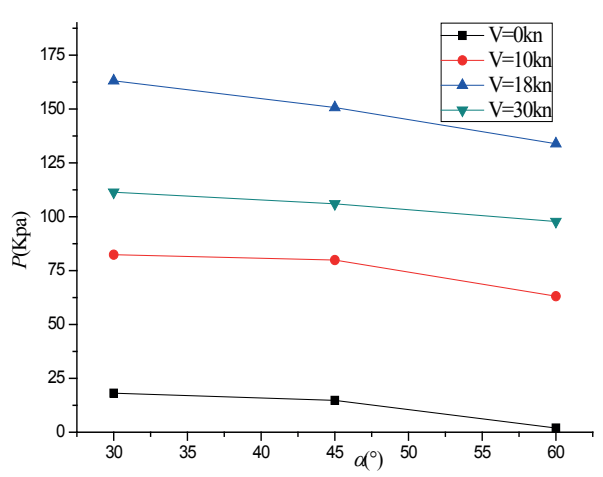

(b) Pressure of green water

Fig. 9. Green water height and pressure of different velocities $(\lambda / L=1.0, H=9 m)$

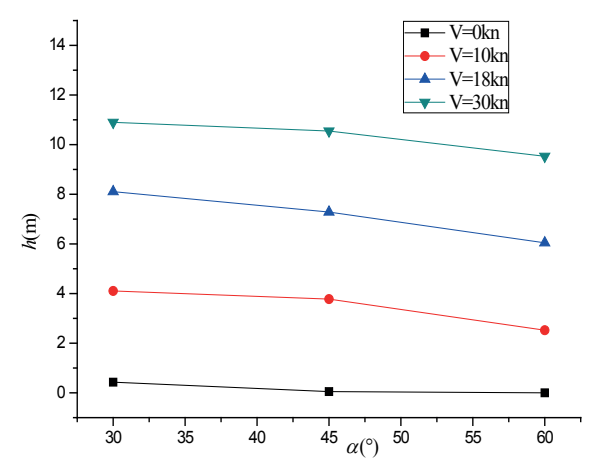

(a)Height of green water

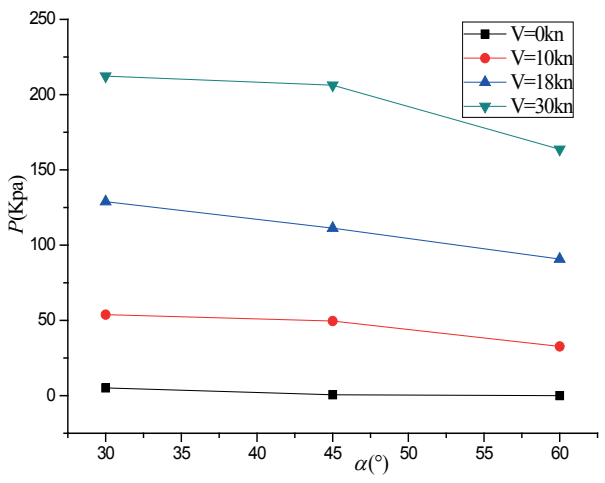

(b) Pressure of green water

Fig. 10. Green water height and pressure of different $a(\lambda / L=1.2, H=9 m)$

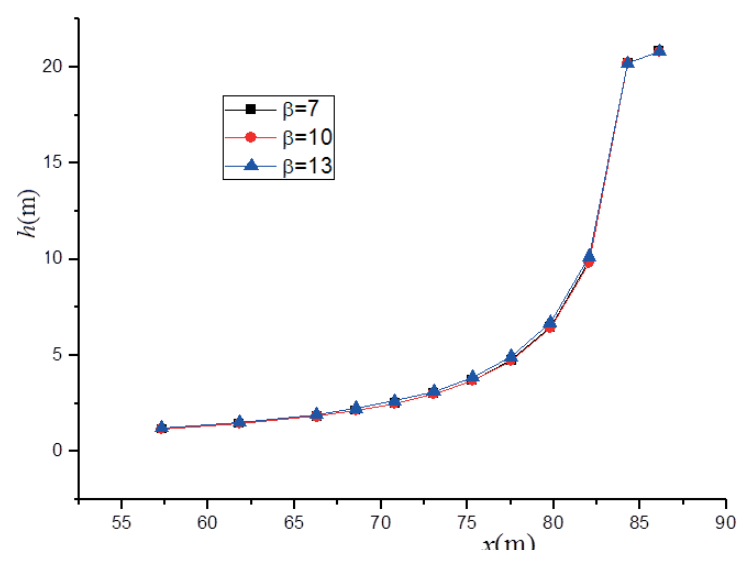

(a)Height of green water

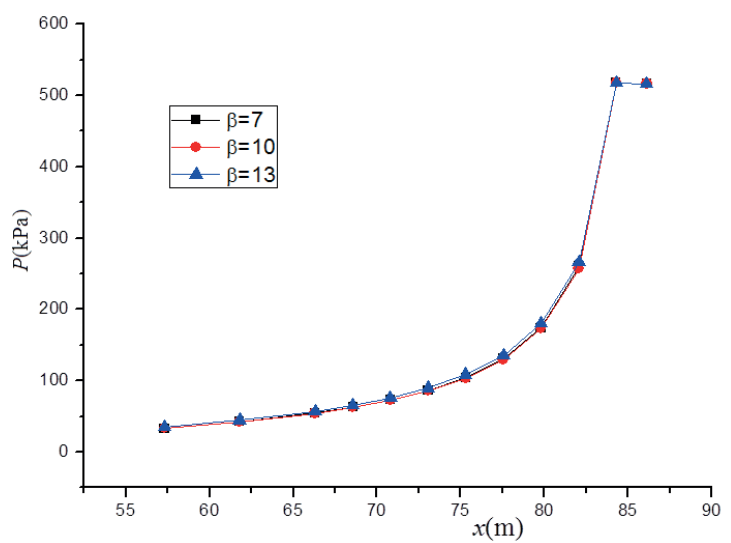

(b) Pressure of green water

Fig. 11. Green water height and pressure of different $b(V s=30 \mathrm{kn}, \lambda / L=1.2$, $H=9 m$ )

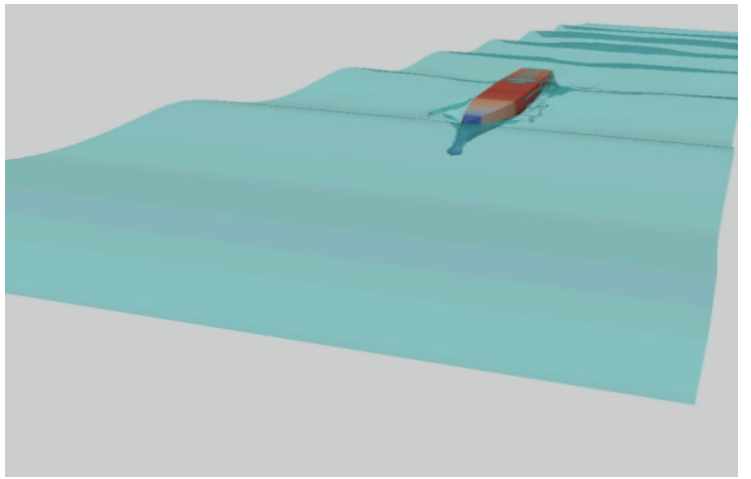

Fig. 12. Numerical wave tank and CFD model

In summary, the green water of tumblehome hull mainly affected by the wave height, speed and $\lambda / L$. The effects of wave height on green water is the most significant, height and pressure of green water will increase with wave height. The influence of speed and $\lambda / L$ is relatively small. The influence of speed on green water is different on different wave length. If $\lambda / L=0.8,1.0$, the height and pressure of green water first increase then decrease. As $\lambda / L=1.2$, the height and pressure of green water increase with the increase of speed. As a whole, as $\lambda / L=0.8$, the green water cannot occur easily; When $\lambda / L=1.0$, it is more prone to occur the green water; When $\lambda / \mathrm{L}=1.2$, and the maximum value of green water is $30 \mathrm{kn}$.

Change of stem inclination angle causes different shapes of hull under the waterline. Therefore, configuration A, C, E have different motion responses in regular wave. With the analysis of stem inclination angle effecting on green water like Figure $7 \sim$ Figure 11 shown. When $\lambda / L$ is 0.8 , with the increasing of stem inclination angle, the height and pressure of green water will increase, the height and pressure of green water will decrease at low speed. When $\lambda / L$ is 1.0 or 1.2 , with the increasing of stem inclination angle, the height and pressure of green water will decrease, the decreasing trend is more obviously at high speed.

It can be found that, the stem inclination angle has a great influence on the green water of tumblehome hull in regular waves. The proper increase of stem inclination angle can 
reduce the occurrence of green water, and the external load generated by green water can also be reduced.

The differences of the three models: configuration $\mathrm{B}\left(\alpha=45^{\circ}\right.$, $\left.\beta=7^{\circ}\right)$, configuration $C\left(\alpha=45^{\circ}, \beta=10^{\circ}\right)$ and configuration $D$ $\left(\alpha=45^{\circ}, \beta=13^{\circ}\right)$ only reflected in the different deck width. The three height and the pressure curves of green water are almost coincident under different speeds with the change of freeboard inclination angle. The difference of height and pressure is very small among the three models, and the relative change of configuration $\mathrm{C}$ and $\mathrm{D}$ compared with configuration $B$ is less than $1 \%$. One side, the motion response of the three ships in regular waves is consistent, the height of green water at bow vertex is consistent; on the other side, The difference of deck width caused by different freeboard inclination angle is very small, did not have a significant impact on green water. The difference of green water with configuration $\mathrm{B}$, configuration $\mathrm{C}$, configuration $\mathrm{D}$ is small. The effect of green water on tumblehome hull in regular waves is not obvious in freeboard inclination angle. Figure 10 shows the influence of freeboard inclination angle on the green water. When speed is $30 \mathrm{kn}, \lambda / L=1.2, H=14 \mathrm{~m}$.

In order to measure the pressure distribution of the ship's bow, the number of measuring point is set as shown in Figure 13.

The green water is closely related to the motion of the hull in waves. In regular wave, after the movement of the hull is stable, the green water appears periodically, from Figure 14 and Figure 15 it can be found that the pressure amplitude of those measuring points show a periodic change. From Figure 14 it can be found that at zero speed the pressure amplitude of the measuring points on the deck is markedly different. The maximum pressure point is closer to the bow and the pressure at IP12, which is farthest from the bow, has tended to be zero. Generally, the closer to the bow the amplitude is greater. As shown in Figure 15, at the speed of $1.46 \mathrm{~m} / \mathrm{s}$, the pressure amplitude of the measuring points on the bow also indicate that the closer to the bow the amplitude is larger. However, the relative change is smaller. Comparing Figure 14 with Figure 15, as the wave-length is $4.5 \mathrm{~m}(\lambda / \mathrm{L}=1.0)$, the phenomenon of green water is more likely to stabilize with forward speed and the pressure amplitude also significantly greater than zero speed.

Figure 16, Figure 17 and Figure 18 give the comparison of numerical calculation results of dam-break model and experimental results measured in towing tank. According to the results of numerical calculation, three typical working conditions of configuration $\mathrm{C}$ are selected for model test in the towing tank of Harbin Engineering University (HEU), the working condition $1(\mathrm{v}=10 \mathrm{kn}, \mathrm{H}=12 \mathrm{~m}, \lambda / \mathrm{L}=1.0)$, working condition $2(\mathrm{v}=18 \mathrm{kn}, \mathrm{H}=9 \mathrm{~m}, \lambda / \mathrm{L}=1.0)$ and working condition $3(\mathrm{v}=30 \mathrm{kn}, \mathrm{H}=6 \mathrm{~m}, \lambda / \mathrm{L}=1.0)$. The green water height and pressure on the deck of model test results are compared with the numerical simulation results of dam-break flow models.

By comparing the results of model test with dam-break flow calculation results, the following conclusions are summarized:
1. The calculation results of heights and pressures of green water are less than those of model test. However, the trend of green water height distribution on deck of the two methods is similar. The results of the dam-break flow calculation at low speed are closer to the model test results than high speed.

2. For the ignorance of green water on motions prediction methods, the motion prediction results do not match the model test results well. Therefore, the errors of green water results at some points from dam-break flow model are large comparing with model test results.

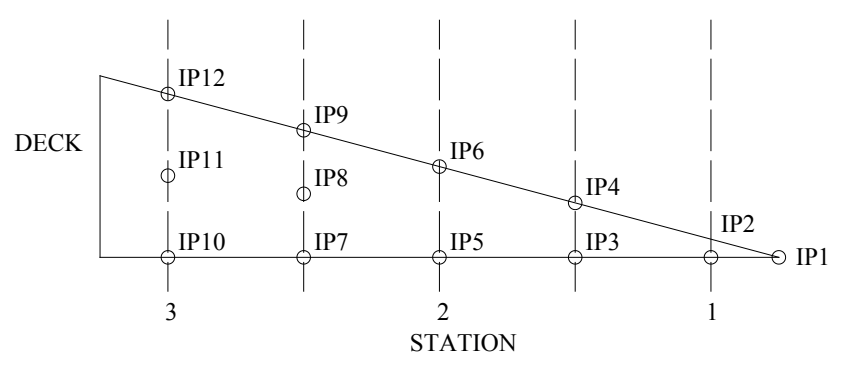

Fig. 13. CFD simulation calculation of deck pressure measuring point layout diagram

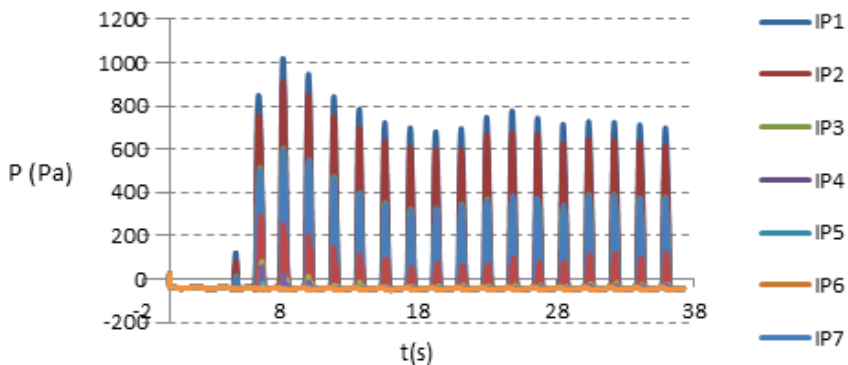

Fig. 14. Wave pressure on the measurement point of $\operatorname{deck}(\mathrm{Vm}=0 \mathrm{~m} / \mathrm{s}, \lambda=4.5 \mathrm{~m}$, $H=0.225 \mathrm{~m})$

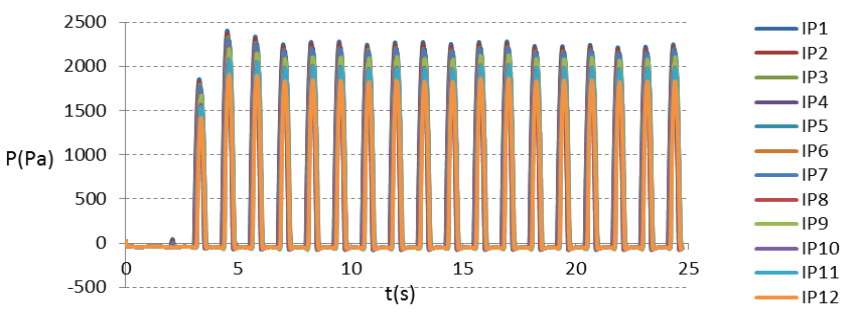

Fig. 15. Wave pressure on the measurement point of deck $(\mathrm{Vm}=1.46 \mathrm{~m} / \mathrm{s}$, $\lambda=4.5 \mathrm{~m}, H=0.225 \mathrm{~m}$ ) 


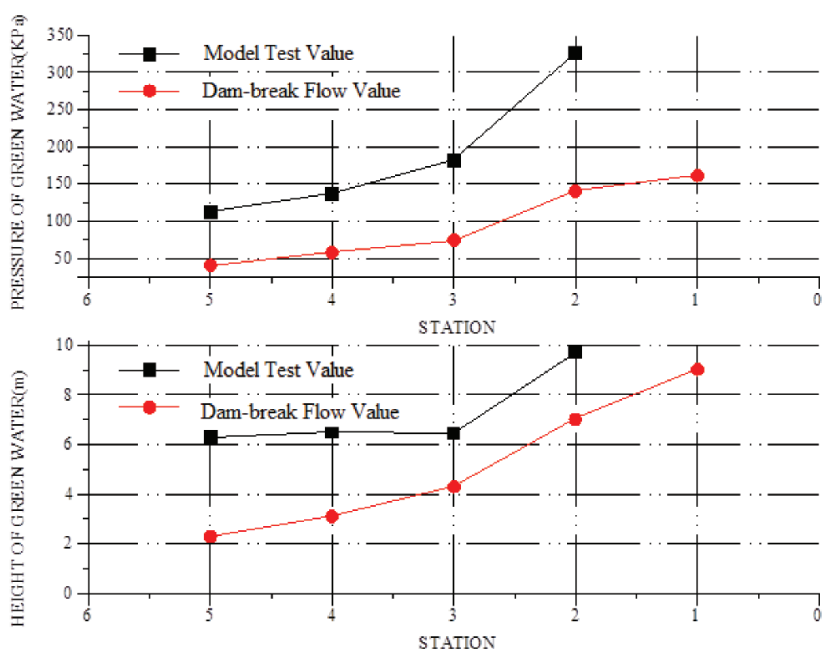

Fig. 16. Comparison of numerical and experimental values ( $V s=10 \mathrm{kn}$, $H=12 \mathrm{~m}, \lambda / L=1.0$ )

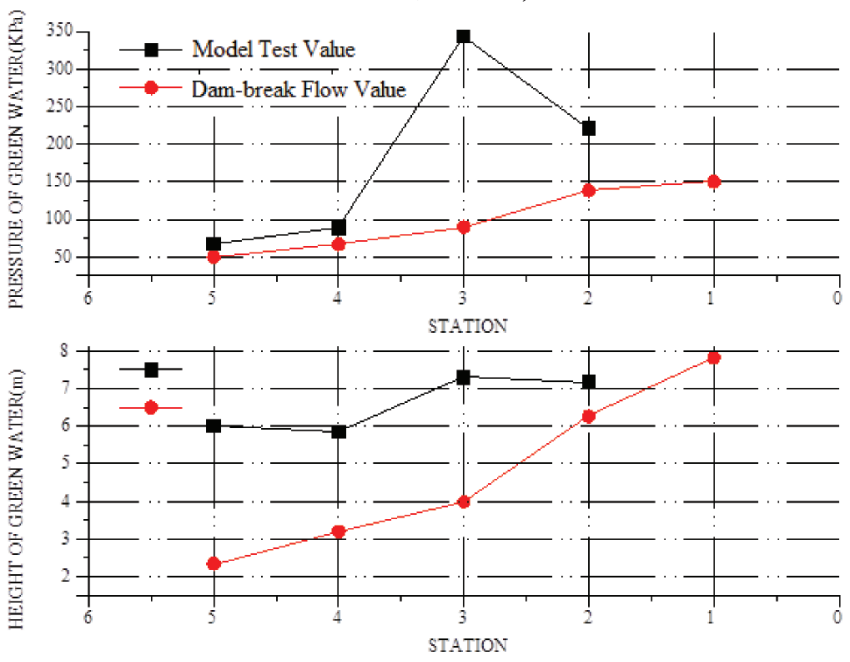

Fig. 17. Comparison of dam-break flow and experimental values ( $V s=18 \mathrm{kn}$, $H=9 m, \lambda / L=1.0$

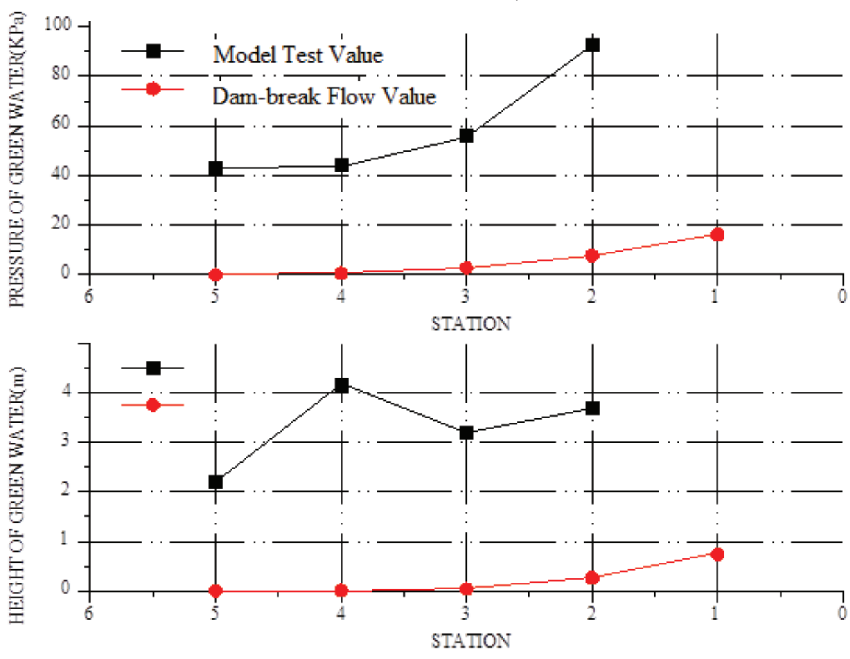

Fig. 18. Comparison of dam-break flow and experimental values (Vs=30kn, $H=6 m, \lambda / L=1.0)$

\section{CONCLUSIONS}

The green water of tumblehome hull is different from traditional flare hull form induced by the complex hull shape. By analyzing the influence of wave parameters and dimensions of hull on green water of tumblehome hull, and comparing with the test results, some conclusions are summarized as follows:

1. Wave height has a great influence on green water of tumblehome hull, with the increase of wave height, the green water are more prone to happen and the loads of green water on deck is larger. The effect of wavelength on the generation of green water and the impact of wave loads will be varied with speed. Overall, as $\lambda / L=1.0$, the green water is most prone to happen; and as $\lambda / L=1.2$, at the speed of $30 \mathrm{kn}$, the green water height is maximum.

2. The results of potential flow theory calculation and $3 \mathrm{D}$ CFD simulation indicate that, the height of green water is small under lower sea state, and green water happens only on a small area near the bow, along the ship breadth direction from the longitudinal section to the side of the descending. In a high state of the sea, the height of green water is large, and the pressure on bow deck is very small in the direction of the ship length and breadth.

3. The relative change of the green water height caused by the change of freeboard inclination angle is small, and the effect of the stem inclination angle on green water in the regular wave is obvious. With the increase of the stem inclination angle, the height and pressure of green water are obviously reduced.

4. The results of CFD simulation show that the process of inversion of the ship in the regular wave is closely related to the response of the hull, and the relative position of waves and hull has a direct impact on green water.

5. The calculation results of heights and pressures of green water are less than those of the model test. The results of the theoretical calculation at low speed are closer to the test results. The errors of green water results at some points from dam-break flow model are large compared with model test results for the ignorance of influence of green water on motion prediction.

\section{ACKNOWLEDGEMENTS}

The authors would like to appreciate A.P. Kangping Liao for his help of CFD simulation. Thanks to the financial support provided by the Nation Defense Fundation (6140241010104).

\section{BIBLIOGRAPHY}

6. Zhang Jinfeng, Gu Min, Wei Jianqiang. Model testing and theoretic study of the longitudinal motions in waves of low-freeboard stealthy ship. Journal of Ship Mechanics. No.2 Vol. 13, 2009, pp.169-176

7. WEI Chengzhu, LI Yinghui, YU Shengjie, YI Hong. 
Experimental Study on the High Speed Mono-WavePiercing Boat. J. Shanghai Jiaotong Univ (Sci.). No.5 Vol.21, 2016, pp. 524-529

8. JIANG Zhifang, HUANG Weigang, QIU Liaoyuan et al. Simulation Analysis of Non-Linear Roll of a Tumblehome Hull Ship. Chinese Journal of Ship Research. No.1 Vol. 9, 2014, pp.40-51

9. PHAM X P, VARYANI K S. Evaluation of green water loads on high-speed containership using CFD. Ocean Engineering. No.5-6 Vol. 32, 2005, pp. 571-585

10. ZHANG Yongxiang, CHEN Jingqiu. Numerical simulation of 2-D dam-break flow wave by using conservation element and solution element method. Journal of Hydraulic Engineering, No.36 Vol.10, 2005, pp.1224-1229

11. Yonguk Ryu, Kuang-An Chang, Richard Mercier. Application of dam-break flow to green water prediction. Applied Ocean Research. No.3 Vol.29, 2007, pp. 128-136

12. SAMES P C. Prediction of green water loads for a roro passenger ferry. Proceedings of OMAE 21st International Conference on Offshore Mechanics and Artic Engineering, 2002, Oslo, Norway.

13. LIANG Xiufeng, YANG Jianmin, LI Xin., Numerical simulation of Green water on FPSO. Journal of Hydrodynamics. No.2 Vol. 22, 2007, pp. 229-236

14. FUNENO I. On viscous flow around marine propellershub vortex and scale effect. Proceedings of New S-Tech. No.238 Vol. 2002, 2002, pp. 17-27

15. LIU Zhihua, XIONG Ying, ZHANG Yongkun. Study on separating calculation method for ship model wave resistance based on RANS equation and its availability. Journal of Ship Mechanics, No.11 Vol.14, 2010, pp.1213-1218

16. M. Go'mez-Gesteira, D. Cerqueiro, C. Crespo, R.A. Dalrymple. Green water overtopping analyzed with a SPH model. Ocean EngineeringNo.2 Vol.32, 2005, pp. 223-238

17. D. Le Touzé, A. Marsh1, G. Oger, P.-M. Guilcher, C. Khaddaj-Mallat1, B. Alessandrini1, P. Ferrant. SPH simulation of green water and ship flooding scenarios. No.5 Vol.22, 2010, pp. 231-236

18. Kristian Bendix Nielsen, Stefan Mayer. Numerical prediction of green water incidents. Ocean Engineering. No.3-4 Vol.31, 2004, pp. 363-399

\section{CONTACT WITH THE AUTHOR}

Hui Li, Assoc. Prof. Ph.D.

e-mail:huili@hrbeu.edu.cn

College of Shipbuilding Engineering

Harbin Engineering University

Harbin Heilongjiang

150001 China

CHINA 